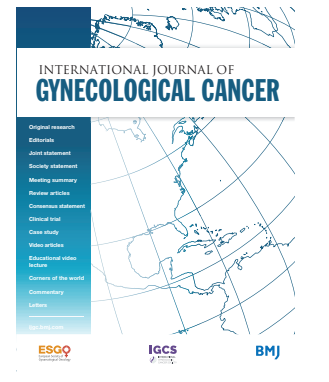

Division of Gynecologic Oncology, Department of Obstetrics and Gynecology and Reproductive Biology, Brigham and Women's Hospital, DanaFarber Cancer Institute, Harvard Medical School, Boston, MA 02115, USA

\section{Correspondence to} Dr Kevin Elias, Gynecologic Oncology, Brigham and Women's Hospital Department of Obstetrics and Gynecology, Boston, MA 02115, USA; KELIAS@BWH.HARVARD.EDU

Received 6 August 2020 Accepted 10 August 2020 Published Online First 19 August 2020

\section{SLinked}

- http://dx.doi.org/10.1136/ ijgc-2020-001683

Check for updates

(c) IGCS and ESGO 2020. № commercial re-use. See rights and permissions. Published by BMJ.

To cite: Elias K. Int J Gynecol Cancer 2020;30:1479.

\title{
Knowing but not doing: the state of global enhanced recovery after surgery in gynecologic oncology
}

Kevin Elias

Surgical habits initiated in the early 20th century, such as preoperative fasting, bowel cleansing, liberal intravenous fluid administration, and intraperitoneal drainage, arose in response to the condition of medical care at the time. Infections were common, suture materials were crude, and laboratory and imaging investigations to evaluate complications were limited. One would expect that modern surgical practice in the era of antibiotics, rapid diagnostics, advanced materials, and pharmacologic innovations would differ markedly from its predecessor. Unfortunately, in an important global survey of current gynecologic oncology practice, Dr. Bhandoria and colleagues show us in this issue that recognizing what should be the standard of care is not the same as implementing reform. ${ }^{1}$ Indeed, practicing oncologic surgery today using the same perioperative protocols in place 50 years ago is as shortsighted as administering chemotherapy today using a pharmacopeia found in the clearance bin at a secondhand bookstore. The advent of enhanced recovery after surgery (ERAS) programs has rightly forced a reckoning with dogma across surgical disciplines. ${ }^{2}$ While gynecologic oncology has been one of the most active fields in promoting and disseminating these updated approaches to surgical care, significant barriers remain to effecting institutional change.

Critics may note that ERAS is not a perfect science. Even with its roots in evidence-based medicine, many of the guidelines are based on limited testing in clinical trials. ${ }^{3}$ Still, the counter arguments fall short. What practicing surgeons today in good faith would promote the liberal use of opioids, prolonged immobility, volume overload, and starvation as highquality care? Yet, in the present study, we see that more than half of respondents around the world admit that this is the state of their current practice, with high percentages reporting the routine use of gastric decompression (56\%), extended intravenous fluid infusions (76\%), and delayed reintroduction of normal diets $(66 \%)$.

What is perhaps most surprising about these findings is that overwhelming majorities of respondents felt that ERAS protocols did not increase complication rates $(90 \%)$ and were generally safe $(78 \%)$. So where is the disconnect between knowledge and practice? As a specialty, we should view advances in the quality of perioperative care through the same lens as we view new chemotherapy agents or surgical instruments. Efforts should be made at every level to revisit and standardize perioperative pathways, audit compliance, and track outcomes. As a discipline, we owe our patients a commitment to the highest quality of care, and harmonizing guidelines with practice remains a top priority throughout the field.

Twitter Kevin Elias @kevin_elias

Contributors KE is the sole author.

Funding The authors have not declared a specific grant for this research from any funding agency in the public, commercial, or not-for-profit sectors.

Competing interests None declared.

Patient consent for publication Not required.

Provenance and peer review Commissioned; internally peer reviewed.

\section{REFERENCES}

1 Bhandoria GP, Bhandarkar P, Ahuja V, et al. Enhanced recovery after surgery (ERAS) in gynecologic oncology: an international survey of peri-operative practice. Int $J$ Gynecol Cancer 2020;30:1471-8.

2 Ljungqvist O, Scott M, Fearon KC. Enhanced recovery after surgery: a review. JAMA Surg 2017;152:292-8.

3 Nelson G, Bakkum-Gamez J, Kalogera E, et al. Guidelines for perioperative care in gynecologic/ oncology: enhanced recovery after surgery (ERAS) society recommendations - 2019 update. Int J Gynecol Cancer 2019;29:651-68. 